\title{
Biotrophic Fungi Infection and Plant Defense Mechanism
}

\section{Solomon Abera Gebrie*}

Plant Biotechnology Research, P.O. Box 31, Holeta, Ethiopia

\begin{abstract}
Biotrophic pathogens derive nutrients from living cells by maintaining host viability. This host Maintenance sustain through highly specialized structural and biochemical relations. For valuable virulence activity biotrophic fungi have: highly developed infection structures; limited secretory activity, carbohydrate rich and protein-containing interfacial layers; long-term suppression of host defense; haustoria that used for nutrient absorption and metabolism. Plant defenses biotrophic fungal pathogen by penetration resistance and program cell death (PCD). Plant strengthens cell wall and membrane to halt spore germination and prevent the formation of the haustorium by Penetration resistance. The second resistance mechanism applied inside the penetrated epidermal cell that terminates nutrient supply to fungi for further development by induction of invaded program cell death. Plant innate immune responses occur through two basic interconnected forms: pathogen-associated molecular patterns (PAMP)-triggered immunity (PTI) and effector-triggered immunity (ETI) to activate defense signal molecules. However, Biotrophic fungi have several mechanisms to defend their effectors from plant receptor molecules. Once the fungal effector passes plant defense mechanism the plant will not resist. Subsequently the plant reduces production of defense signaling molecule like salicylic acid. This review overviews recent knowledge of biotrophic fungi infection and plant defense strategies.
\end{abstract}

Keywords: Effectors; Biotrophic; ETI; PTI; Signal-molecule Introduction

Toxin-antitoxin (TA) systems are ever-present bacterial systems that may function in genome maintenance and metabolic stress organization, but are also thought to play a role in virulence by helping pathogens survive stress. TA systems are now thought to increase virulence through mechanisms that may include increased stress resistance, persister cell formation, or biofilm formation [1]. Pathogen effectors may be differ structurally even the can bind the same regulatory element in regulated promoter regions. For instance AvrRxo1-ORF2 binds AvrRxo1-ORF1, it is structurally different from typical effector-binding chaperones, in that it has a distinct fold containing a novel kinase-binding domain [2]. The gene structure and cis-acting regulatory elements of effector genes are highly conserved between in different pathogens and report several novel effector genes these regulate pathogene responsive genes like WRKY53 [3].

Plant pathogens are classified based on their nutrition methods. Biotrophic pathogens derive nutrients from living cells by maintaining host viability. This lifestyle contrasts with that of necrotrophic pathogens actively kill host tissue as they grow on the contents of dead or dying cells [4]. A third group, hemibiotrophs, show both forms of nutrient via shifting from an early biotrophic phase to necrotrophy latterly. The duration of the biotrophic or necrotrophic phase varies significantly among hemibiotrophic pathogens. These different classified pathogens show differences in immune responses because of their modes of nutrient uptake [5].

The biotrophic fungi and their plant host have highly specialized relationship structurally and also biochemically. Biotrophc fungi penetrate the host cell wall and colonizing the intercellular space using feeding structures like haustoria to absorb nutrients and suppress host defenses without disrupting the plasma membrane [6,7]. A constant balance between virulence and evading host detection show a very sophisticated form of pathogenesis of biotrophic fungi. By contrast, necrotrophs overpowering the host by utilizing a variety of secreted pathogenicity and virulence factors throughout infection instead of producing specialized infection structures.

By their feeding acitivities, biotrophic fungi create a nutrient sink to the infection site, so that the host is disadvantaged and shows serious yield lost. In many ways, this type of parasitism is very sophisticated - keeping the host alive as a long-term source of food. In this review the most important groups of biotrophic fungi plant pathogens like powdery mildew fungi (Ascomycota), the rust fungi (Basidiomycota) and plant defense mechanism have been considered.

\section{Biotrophic fungi infection mechanisms}

Plant pathogens have to pass the complex multilayered defense system for compatible interaction. Fungus protection may include fungal chitin shield, scavenger, which protect the fungal cell wall and the chitin fragments from chitinases. For example effector of Cladosporium fulvum holds a functional chitin-binding domain [8]. Plants secrete beta-1,3-glucanases to damage fungal cell walls but some pathogen produces glucanase inhibitor protein. Other effectors (proteinase inhibitors and phytoalexin detoxifying enzymes) may aid the pathogen success too.

For the success of pathogenesis including attachment, host recognition, penetration and proliferation biotrophic fungi form infection structure. The structure formation is restricted by regulated gene expression and complex regulatory pathways [9]. For valuable virulence activity biotrophic fungi have: highly developed infection structures; limited secretory activity, especially of lytic enzymes; carbohydrate rich and protein-containing interfacial layers, which separate fungal and plant plasma membranes; long-term suppression of host defense; haustoria that used for nutrient absorption and metabolism. Biotrophic fungi also have several mechanisms to defend their effectors from plant receptor molecules. Once the fungal effector

*Corresponding author: Solomon Abera Gebrie, Plant Biotechnology Researcher, P.O. Box 31, Holeta, Ethiopia, Tel: +251911568273; E-mail: solomonabera19@gmail.com

Received September 08, 2016; Accepted September 29, 2016; Published September 30, 2016

Citation: Gebrie SA (2016) Biotrophic Fungi Infection and Plant Defense Mechanism J Plant Pathol Microbiol 7: 378. doi: 10.4172/2157-7471.1000378

Copyright: () 2016 Gebrie SA. This is an open-access article distributed under the terms of the Creative Commons Attribution License, which permits unrestricted use, distribution, and reproduction in any medium, provided the original author and source are credited. 


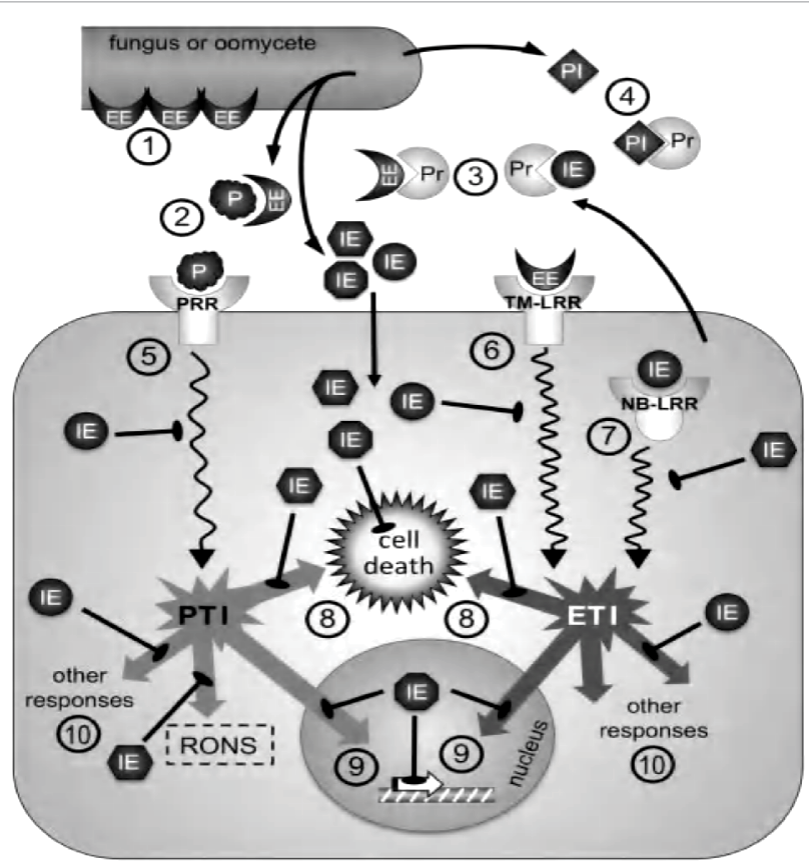

Figure 1: Defense effector entering the host cell through several pathways. (EE=Extracellular effectors outside apoplast. IE= intracellular effectors. (1) Prevent effector from cell walls or (2) prevent recognition receptors (PRR) Plants secrete proteases $(\operatorname{Pr})(3)$ to degrade IE or EE, but pathogens (4) secrete protease inhibitors (PI) to block those proteases. Recognition of PAMPs by PRRs (5) produces signaling events that trigger PAMP-triggered immune responses $(\mathrm{PTI})$. Recognition of EE by trans-membrane leucine-rich receptors (TM-LRRs) (6) or recognition of IE by nucleotide-binding leucine-rich receptors (NB-LRRs) (7) leads to effector-triggered immune responses (ETI). Signaling events for both PTI and ETI may be inhibited by intracellular effectors. PTI and ETI both produce programmed cell death (8), and effectors may inhibit the triggering of cell death or the cell death machinery itself. PTI and ETI both involve transcriptional changes (9), and nuclear-targeted effectors may interfere with signaling within the nucleus or transcriptional events directly. PTI and ETI involve numerous other responses (10), including the production of reactive oxygen and nitrogen species (RONS), and effectors may interfere with those responses as well)

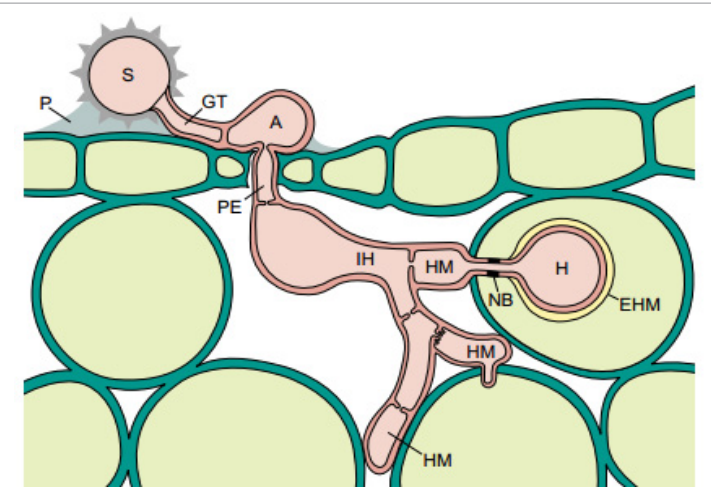

Figure 2: Biotrophic infection by Uromyces fabae (dikaryon). A germ tube (GT) emerges from anurediospore (S) attached to the host by an adhesion pad $(P)$. After recognition of the guard cell lip, anappressorium (A) develops over the stomatal pore. The penetration hypha (PE) penetrates into the substomatal chamber and elongates into an infection hypha $(\mathrm{IH})$. When the tip of the infection hypha contacts a host cell wall, a haustorial mother cell $(\mathrm{HM})$ is formed from which the haustorium $(\mathrm{H})$ invades the host cell. Unique features of the dikaryotic haustorium are the dark-staining neck-band (NB) around the haustorial neck and the interfacial, extrahaustorial matrix (yellow) surrounded by the extrahaustorial membrane (EHM). After forming the first haustorium, the infection hypha branches and further intercellular hyphae, haustorial mother cells (HM) and haustoria are formed. passes plant defense mechanism the plant will not resist. Subsequently the plant reduces production of defense signaling molecule like salicylic acid [10] (Figure 1). To emphasize the infection process in host plant by biotrophic fungi are explained here.

Cladosporium fulvum: C. fulvum is a biotrophic fungal pathogen that causes leaf mould of tomato [11]. The infection, colonization, and suppression of host defenses by $\boldsymbol{C}$. fulvum are mediated by a number of effector proteins [12]. In order to avoid host recognition by host PRRs C. fulvum secretes the effector Ecp6 that contains a LysM chitin binding domain [13]. To restrict the release of chitin oligosaccharides by binding chitin in the intact fungal cell wall C. fulvum also secretes the Avr4 $[8,14]$. In addition to chitin binding proteins, secretes the effector Avr2, which inhibits plant extracellular cysteine proteases required for basal defense also secreted by $C$. fulvum for successful host defense suppression [15].

Ustilago maydis: $U$. maydis is a biotrophic fungus that causes smut maize. U. maydis penetrate the plant cell wall and develops hyphae that are enclosed by the plant plasma membrane and are considered to interface for nutrient uptake and signal communication [16]. Several genes of this pathogen are up-regulated at the time of infection for the suppression of host defense mechanism [12]. Among the most predicted $U$. maydis effectors, Pep1, which is a small (178 amino acids) protein required for successful invasion of epidermal cells of Zea mays [17]. Inoculation of leaves with deletion mutants of $U$. maydis lacking Pep1 led to the failure of the pathogen to establish a compatible interaction with the host. The secreted hydrophobin, Hum3, and the hydrophobic repetitive and secreted protein, Rsp1 effectors are involved in cell adhesion and surface coating also play an important role in infection process of $U$. maydis [18].

Blumeria graminis: B. graminis is an obligate biotrophic fungus that causes powdery mildew disease on wheat (B. graminis f. sp. tritici) and barley (B. graminis f. sp. hordei). B. graminis grows as filamentous hyphae on the leaf surface. However after penetrating the wall of the underlying epidermal cells it forms a specialized feeding structures called a haustoria, which surrounded by an intact plant plasma membrane (Figure 2). Recently about 248 candidate secreted effector proteins (CSEPs), less homology with other related species, have been identified in the B. graminis f. sp. hordei genome [19]. The previously identified AVRa10 and AVRk1efectors have important role infection enhancement [20].

Melampsora lini: M. lini is a rust biotrophic fungus that causes flax (Linum usitatissiumum) rust. Like powdery mildews, rust infection involves formation of haustoria, but rust hyphae reproduce within the leaf rather than on the leaf surface. AvrL567, first identified flax rust effector protein was recognised by the L6, L5, and L7 R proteins [21]. Because of diversifying selection this effector has undergone about twelve variants, some of which through altering surface exposed amino acid residues have now escaped recognition by the cognate $\mathrm{R}$ proteins $[22,23]$. Other three secreted flax rust effector proteins, AvrM, AvrP123 and AvrP4 have been identified, which have important role in host defense suppression [24].

Erysiphe necator: E. necator is an obligate biotrophic fungus that causes powdery mildew in grapevine. This pathogen fully depends on photosynthesis-active tissues to complete its life cycle. When a conidiospore of E. necator lands on the epidermis of photosynthesisactive tissues, it germinates to form a lobed appressorium. Its germination and development involves through the secretion of fungal lytic enzymes such as cutinases esterases and lipases, which leads to the release of long-chain fatty acid derivatives $[25,26]$. A haustorium 
is a specialized intracellular structure, formed from the lower surface of the appressorium by penetration peg emerges that penetrates the cell wall and invades the host epidermal cell. The haustorium is an interface between the host cell and the fungus that facilitates the dynamic exchange of molecules derived from both fungal and host cells. The fungus obtains amino acids, hexoses, vitamins, and other nutrients from host cells, through the haustorium. If the interaction is compatible, the fungus proliferates via hyphae across the surface at regular intervals. To start a new cycle of infection, after 5-25 days sporulation occurs in the form of conidiophores [27]. During the whole infection process secretion of effecter proteins takes place to suppress host defense mechanism. Adapted PM species are able to successfully penetrate their host plant by secreting effector proteins that suppress host PTI. However, successful penetration by the adapted PM species has been shown to be dependent on the presence of a functional allele of the Mildew resistance Locus O (MLO) in a range of host species [28-31]. Based on these result the suggestion goes to, adapted PM species are able to utilize MLO proteins to suppress host PTI by the secretion of an effector that targets MLO. For instance Arabidopsis PM susceptibility protein AtMLO2 acts as a susceptibility factor for infection of by Pseudomonas syringae (bacterial pathogen), which is targeted by the P. syringae effector HopZ [32].

\section{Plant Defenses Against Biotrophic Fungal Pathogens}

There are two main strategies that plants use to restrict the invasion and growth of biotrophic fungal pathogens: penetration resistance and programmed cell death (PCD)-mediated resistance. Plant strengthens cell wall and membrane to halt spore germination and prevent the formation of the haustorium by Penetration resistance. The second resistance mechanism applied inside the penetrated epidermal cell that terminates nutrient supply to fungi for further development by induction of invaded program cell death.

Plant innate immune responses occur through two basic interconnected forms: pathogen-associated molecular patterns (PAMP)-triggered immunity (PTI) and effector-triggered immunity (ETI) [33]. By the interaction of pathogen effector proteins and extracellular pattern-recognition receptors in the plasma membrane of the host cell PTI is activated [34]. Once PAMP detected by patternrecognition receptors activation of multiple defense responses, like the generation of reactive oxygen species, defense genes expression, biosynthesis of defense hormones, phytoalexin biosynthesis, and cell wall strengthening happened in the host cell $[35,36]$. PTI offers protection against the majority of microbes that plants face. However certain isolates have become 'adapted' to a specific host through revolution [33]. Plant acquires resistance (R) proteins that specifically recognize pathogen effectors to activate ETI. Because of $\mathrm{R}$ protein interacton with effectors directly or indirectly defense response that overlap with PTI will be activated [37]. ETI commonly associated with PCD that prevents biotrophic pathogens from acquiring nutrients and completing their life cycle.

\section{Pamp-Triggered Immunity Against Biotrophic Fungi}

Penetration resistance is the major component of PTI against non-adapted biotrophic fungi. In Arabidopsis and barley three PENETRATION (PEN) genes (PEN1, PEN2, and PEN319-21) involve to combined action of Penetration resistance and PTI [38]. PTI responses are selected for its immune enhancement without much fitness cost. Due to the low specificity in pathogen recognition PTI may not be beneficiary for plant in the infection of adapted biotrophic pathogen.
Plants can evaluate the effectiveness of PTI responses. For instance, increasing MAMP signaling may be interpreted as an insufficiency of early responses. If the early responses are enough, plants can terminate unnecessary additional immune responses. In the case of inadequate early responses to amplify the signal for burlier responses in a later stage plants may use the four-sector network. The amplified signal involves as positive feedback loops. As the result PTI shows synergistic communications among the sectors [31,39]. The strong immunity triggered by treatment of plants with flg22 one day prior to inoculation with virulent $P$. syringae because of higher concentration of flg22 per number of plant cells responding [40]. This could be because of early weak response of PTI that interpreted by the plant resulting late foursector mediated network strong immunity.

Because of unhurried initiate of PTI can offer adapted biotrophic fungi pathogens opportunities to well hold up with PTI signaling. Weak PTI signaling can easily suppress by Low concentrations of effectors. Therefore there could be vulnerable synergistic interactions among the sectors by inactivation of one of the late signaling sectors.

\section{Effector-Triggered Immunity Against Biotrophic Fungi}

R-genes in plants encode proteins with nucleotide binding (NB) site - leucine-rich repeat (LRR) domains [34]. These NB-LRR proteins particularly detect the microbial effector molecules and initiate ETI, which is highly effective against biotrophic pathogens. Effectors, in opposite to MAMPs, are properties of strong pathogens. Therefore plants activate strong immune responses in ETI directly after recognition of very low concentration pathogen elicitors by an $\mathrm{R}$ protein in order to secrete strong signals. Consequently, destruction of some signaling sectors by pathogen effectors do not have a large impact on overall immunity. ETI signals strong against suppression by pathogen effectors speed in phase I and network compensation in phase II. Constructing such strong network and dynamics system are vital because pathogens progress much faster than plants; as a result, rapid changes in the effector stock can change the points at which the signaling network is disconcerted. Some effectors like Xoc delivers a type III effector AvrRxo1-ORF1 into rice plant cells can be recognized by disease resistance $(\mathrm{R})$ protein Rxo1 the mechanism and virulence role of AvrRxol is not known [1]. Some pathogens also have type III effector that can function as a TA system toxin, and illustrates the potential of microbiome data to reveal new environmental origins or reservoirs of pathogen virulence factors [2].

\section{Activation of signal molecules in plant defense against biotrophic fungi}

The contact of fungi elicitors with host $\mathrm{R}$ gene product activates primary and secondary signal molecules. Primary/ Early signaling event those observed during disease defense include reactive oxygen species (ROS), protein phosphorylation and ion fluxes. The regulation of these primary event assisted by different genes expressional changes for example WRKY53 transcriptional network regulates oxidative responses to a wide array of stresses [3]. In tomato and parsley cell suspension cultures, fungal elicitors trigger protein phosphorylation [41]. K-252a, Protein kinase inhibitor, blocks the elicitor-induced changes of protein phosphorylation and halts generation of plant defense responses.

Different fungal elicitors have been studied to activate fluxes of $\mathrm{Cl}^{-}, \mathrm{K}, \mathrm{H}^{+}$, and $\mathrm{Ca}^{2+}$ across the plasma membrane [42]. In parsley suspension cells, a temporary influx of $\mathrm{H}^{+}, \mathrm{Ca}^{2+}$ and $\mathrm{Cl}^{-}$are initiated within a few minutes following the insertion of a fungal oligopeptide elicitor [43]. Even fungal eliciter was present, inhibit of ion fluxes and 


\begin{tabular}{|c|c|c|}
\hline Species & Host(s) & Disease \\
\hline Erysiphe graminis & Grasses & Powdery Mildew of Grasses \\
\hline Erysiphe macrospora & Elm & Powdery Mildew of Elm \\
\hline Erysiphe necator & Grape & Powdery Mildew of Grape \\
\hline Leveillula taurica & Cotton & Powdery Mildew of Cotton And Many Other \\
\hline Phyllactinia alnicola & Oak, Alder, Lilac & Powdery Mildew of Oak, Alder, Lilac, Currant \\
\hline Ovariopsis & Hazel, Ash, Birch & Powdery Mildew of Hazel, Ash, Birch \\
\hline Podosphaera leucotricha & Apple, Plum & Powdery Mildew of Apple, Plum \\
\hline Podosphaera macularis & Hops & Powdery Mildew of Hops \\
\hline Coleosporium ipomoeae & Sweet Potato, Pine Needle & Sweet Potato Rust, Pine Needle Rust \\
\hline Cronartium flaccidum & Scotch Pine Blister & Scotch Pine Blister Rust \\
\hline Melampsora epitea & Poplar-Conifer & Poplar-Conifer Rusts \\
\hline Phakopsora pachyrhizi & Soybean & Soybean Rust \\
\hline Kuehneola uredinis & Blackberry & Blackberry Stem and Leaf Rust \\
\hline Phragmidium tuberculatum & Blackberry, Rose, Rosaceous Hosts & Rust of Blackberry, Rose, Rosaceous Hosts \\
\hline Phragmidium violaceum & Blackberry & Blackberry Rust \\
\hline Gymnosporangium sabinae & Pear & Incense Cedar-Pear Rust, Juniper Gall Rust, Pear Trellis Rust \\
\hline Uromyces gladioli & Iridaceae & Rusts of Iridaceae \\
\hline Tranzschelia discolor & Peach & Peach Rust \\
\hline Hemileia vastatrix & Coffee & Coffee Rust \\
\hline
\end{tabular}

Table 1: List of some economically important biotrophic fungi.

defense responses have been observed in the addition of $\mathrm{Ca}^{2+}$ channel blockers [44].

Accumulation oxidative burst or reactive oxygen species (ROS) that include $\mathrm{O}_{2}^{-}$and $\mathrm{H}_{2} \mathrm{O}_{2}$ is another remarkable event occurs as early signaling molecule during pathogen infection [45]. Accumulation of ROS by pathogen effectors maybe linked the activation of ionic influx and protein phosphorylation [32]. Two separate stages of ROS accumulation were observed during plant-biotrophic fungi pathogen communications. The first burst happens after a few minutes of interaction in both resistant and susceptible plant hosts. However, the second burst happens after a few hours of resistant interaction only [46]. For instance, tomato cells these only contain the Pto resistance gene $P$. syringae pv. tomato show the second burst but not in susceptible [47]. Hydrogen peroxide and $\mathrm{O}_{2}$ produced at the time oxidative burst have different roles in plant resistance mechanism. Constitutive regulation of $\mathrm{H}_{2} \mathrm{O}_{2}$ secreting glucose oxidase confirms resistance to the fungal pathogen Phytophthora infestans in the transgenic potato [48]. Furthermore, hydrogen peroxide and $\mathrm{O}_{2}$ involve in plant defense mechanism as antimicrobial molecule, cell wall strengthening and messenger for regulation of defense related genes [49].

Next to the early signal molecules triggered by pathogen infection, the elicitor signals are frequently multiplied via the secretion of secondary signal molecules like ethylene, SA and jasmonates. These three phytohormones are known to play major roles in regulating plant defense responses against various pathogens, [50,51]. SA levels increase in pathogen exposed plant tissues and exogenous SA addition results the induction of pathogenesis related $(\mathrm{PR})$ genes and improved resistance to a wide range of pathogens [52]. Several evidences show SA plays an important role in the activation of defense responses of plant biotrophic fungi [53]. Raising the levels of SA has been linked with the regulation of resistance responses in most plant species via expression of PR genes in the infected and uninfected area to show systemic acquired resistance (SAR) $[54,55]$. Mutants that missed the SA biosynthesis genes were enhanced susceptibility to biotrophic pathogens [56]. Ethylene and jasmonates are triggered plant may be defense against biotrophic fungi. However, some biotrophs, like Erisyphe and P. parasitica spp., avoid triggering ethylene and jasmonates [50]. Therefore, Ethylene and jasmonates dependent defenses are not important in biotrophic fungi- host interaction. Plant innate immune responses PTI and ETI occur to activate defense signal molecules because of the recognition of effectors by pattern-recognition receptors and $\mathrm{R}$ proteins respectively. However, Biotrophic fungi have several mechanisms to defend their effectors from plant receptor molecules and also rapid evolving system of their putative effectors. Once the fungal effector passes plant defense mechanism the plant will not resist. Subsequently the plant reduces production of defense signaling molecule like salicylic acid. This review overviews recent knowledge of biotrophic fungi infection and plant defense strategies (Table 1).

\section{Conclusion}

Plant innate immune responses PTI and ETI occur to activate defense signal molecules because of the recognition of effectors by pattern-recognition receptors and $\mathrm{R}$ proteins respectively. However, Biotrophic fungi have several mechanisms to defend their effectors from plant receptor molecules and also rapid evolving system of their putative effectors. Once the fungal effector passes plant defense mechanism the plant will not resist. Subsequently the plant reduces production of defense signaling molecule like salicylic acid. Understanding of the interaction between pathogen virulence and have been coming a long way. However, several questions yet not answered. Most of fungal effectors function in the cytosol of plant lack clear signals movement mechanism from their first sequence. Therefore, the method how effectors marked and delivered into host plant plasma member is not clear. Because of the diverse fungal effectors and less homology sequence with known proteins make difficult to understand their roles in disease. In biotrophic fungi even few effectors functions as suppression of immune responses, unknown effectors may have involved for the maintenance of host metabolism in order to raise nutrient accessibility for continuous infection. Recently with the help of next generation, sequencing there is a possibility to obtain genome information, even if we cannot study them under in vitro condition. By the help of this generation sequencing, biotrophic fungal genomes include many rapidly evolving putative effectors. This rapid evolution of putative effectors may be because of high selection pressure that applied by the plant's immune recognition method for the development of another pathogenicity approach. Effectors evolution may be also influenced by crop domestication. However there are also unanswered 
question here, is there any special pathogen -host interaction between wild hosts and domesticated plant? Until what level symbiotic and pathogenic fungi show similar host exploitation process? For example, recently two symbiotic fungi showed direct secreted effectors in the host cells $[57,58]$. In order to answer these and other many issues, we have to have better understanding about the roles of effectors in pathogen compatible interaction. Even if there are several effectors the rapid development of genomic tools has great roles to study function of biotrophic fungi effectors in host plant.

\section{Acknowledgement}

First I would like to give my great acknowledgement for GOD, who never apart me so far and forever in each my activity for this work too. Secondly, I would like to thank all my colleagues, who encourage me to try all my best and give their important comment for the completion of this work.

\section{References}

1. Van den Burg HA, Harrison SJ, Joosten M, Vervoort J, De Wit P (2006) Cladosporium fulvum Avr4 protects fungal cell walls against hydrolysis by plant chitinases accumulating during infection. Molecular Plant-Microbe Interactions 19: $1420-1430$

2. Van Eck L, Davidson RM, Wu S, Zhao BY, Botha AM, et al. (2014) The transcriptional network of WRKY53 in cereals links oxidative responses to biotic and abiotic stress inputs. Funct Integr Genomics 14: 351-362.

3. Triplett LR, Shidore T, Long J, Miao J, Wu S, et al. (2016) AvrRxo1 is a Bifunctional Type III Secreted Effector and Toxin-Antitoxin System Component with Homologs in Diverse Environmental Contexts. PLoS ONE 11: e0158856.

4. Tel-Aviv University (2012) Manual. Department of Molecular Biology and Ecology of Plants p: 298.

5. Stone JK (2001) Necrotroph, In: Encyclopedia of plant pathology, OC Maloy, TD Murray (eds.) 2: 81676-81677.

6. Laluk K, Mengiste T (2010) Necrotroph attacks on plants: wanton destruction or covert extortion? Arabidopsis Book 8: e0136.

7. Schulze-Lefert P, Panstruga R (2003) Establishment of biotrophy by parasitic fungi and reprogramming of host cells for disease resistance. Annu Rev Phytopathol 41: 641-667.

8. van Esse HP, Bolton MD, Stergiopoulos L, De Wit P, Thomma B (2007) The chitin-binding Cladosporium fulvum effector protein Avr4 is a virulence factor. Molecular Plant-Microbe Interactions 20: 1092-1101.

9. Kahmann R, Basse $C$ (2001) Fungal gene expression during pathogenesis-related development and host plant colonization. Curr Opin Microbiol 4: 374-380.

10. Mendgen K, Hahn M (2004) Plant infection and the establishment of fungal biotrophy. Current Opinion in Plant Biology 7: 81356-81364.

11. Thomma BP, Van Esse HP, Crous PW, De Wit PJ (2005) Cladosporium fulvum (syn. Passalora fulva), a highly specialized plant pathogen as a model for functional studies on plant pathogenic Mycosphaerellaceae. Mol Plant Pathol 6: 379-393.

12. Djamei A, Schipper K, Rabe F, Ghosh A, Vincon V, et al. (2011) Metabolic priming by a secreted fungal effector. Nature 478: 395-398.

13. De Jonge R, Van Esse HP, Kombrink A, Shinya T, Desaki Y, et al. (2010) Conserved fungal LysM effector Ecp6 prevents chitin-triggered immunity in plants. Science 329: 953-955.

14. Zipfel C, Robatzek S, Navarro L, Oakeley EJ, Jones JD, et al. (2004) Bacterial disease resistance in Arabidopsis through flagellin perception. Nature 428: 764-767.

15. van Esse HP, Van't Klooster JW, Bolton MD, Yadeta KA, Van Baarlen $P$, et al. (2008) The Cladosporium fulvum virulence protein Avr2 inhibits host proteases required for basal defense. Plant Cell 20: 1948-1963.

16. Brefort T, Doehlemann G, Mendoza-Mendoza A, Reissmann S, Djamei A, et al. (2009) Ustilago maydis as a Pathogen. Annu Rev Phytopathol 47: 423-445.

17. Doehlemann G, Van der Linde K, Amann D, Schwammbach D, Hof A, et al. (2009) Pep1, a secreted effector protein of Ustilago maydis, is required for successful invasion of plant cells. PLoS Pathog 5: 478-489.

18. Mueller O, Kahmann R, Aguilar G, Trejo-Aguilar B, Wu A, et al. (2008) The secretome of the maize pathogen Ustilago maydis. Fungal Genet Biol 45 Suppl 1: $563-70$.

19. Spanu PD, Abbott JC, Amselem J, Burgis TA, Soanes DM, et al. (2010) Genome expansion and gene loss in powdery mildew fungi reveal tradeoffs in extreme parasitism. Science 330: 1543-1546.

20. Ridout CJ, Skamnioti P, Porritt O, Sacristan S, Jones JDG, et al. (2006) Multiple avirulence paralogues in cereal powdery mildew fungi may contribute to parasite fitness and defeat of plant resistance. Plant Cell 18: 2402-2414.

21. Dodds PN, Lawrence GJ, Catanzariti AM, Ayliffe MA, Ellis JG (2004) The Melampsora lini AvrL567 avirulence genes are expressed in haustoria and their products are recognized inside plant cells. Plant Cell 16: 755-768.

22. Dodds PN, Lawrence GJ, Catanzariti AM, Teh T, Wang Cl, et al. (2006) Direct protein interaction underlies gene-for-gene specificity and coevolution of the flax resistance genes and flax rust avirulence genes. Proc Natl Acad Sci USA 103: 8888-8893.

23. Wang Cl, Guncar G, Forwood JK, Teh T, Catanzariti AM, et al. (2007) Crystal structures of flax rust avirulence proteins AvrL567-A and -D reveal details of the structural basis for flax disease resistance specificity. Plant Cell 19: 2898-2912.

24. Catanzariti AM, Dodds PN, Lawrence GJ, Ayliffe MA, Ellis JG (2006) Haustorially expressed secreted proteins from flax rust are highly enriched for avirulence elicitors. Plant Cell 18: 243-256.

25. Feng J, Wang F, Liu G, Greenshields D, Shen W, et al. (2009) Analysis of a Blumeria graminis-secreted lipase reveals the importance of host epicuticular wax components for fungal adhesion and development. Mol Plant Microbe Interact 22: 1601-1610.

26. Weidenbach D, Jansen M, Franke RB, Hensel G, Weissgerber W, et al. (2014) Evolutionary conserved function of barley and Arabidopsis 3-Ketoacyl-CoA Synthases in providing wax signals for germination of powdery mildew fungi. Plant Physiol 166: 1621-1633.

27. Delp CJ (1954) Effect of temperature and humidity on the grape powdery mildew fungus. Phytopathology 44: 615-626.

28. Büschges R, Hollricher K, Panstruga R, Simons G, Wolter M, et al. (1997) The barley Mlo gene: a novel control element of plant pathogen resistance. Cell 88: 695-705.

29. Consonni C, Humphry ME, Hartmann HA, Livaja M, Durner J, et al. (2006) Conserved requirement for a plant host cell protein in powdery mildew pathogenesis. Nat Genet 38: 716-720.

30. Bai YL, Pavan S, Zheng Z, Zappel NF, Reinstadler A, et al. (2008) Naturally occurring broad-spectrum powdery mildew resistance in a central American tomato accession is caused by loss of Mlo function. Mol Plant Microbe Interac 21: $30-39$.

31. Koeck M, Hardham AR, Dodds PN (2011) The role of effectors of biotrophic and hemibiotrophic fungi in infection. Cell Microbiol 13: 1849-1857.

32. Low PS, Merida JR (1996) The oxidative burst in plant defense: Function and signal transduction. Physiol Plant 96: 533-542.

33. Dangl JL, Horvath DM, Staskawicz BJ (2013) Pivoting the plant immune system from dissection to deployment. Science 341: 746-751.

34. Boller T, Felix G (2009) A renaissance of elicitors: perception of microbeassociated molecular patterns and danger signals by pattern-recognition receptors. Annu Rev Plant Biol 60: 379-406.

35. Wan J, Zhang XC, Neece D, Ramonell KM, Clough S, et al. (2008) A LysM receptor-like kinase plays a critical role in chitin signaling and fungal resistance in Arabidopsis. Plant Cell 20: 471-481.

36. Meng X, Zhang S (2013) MAPK cascades in plant disease resistance signaling Annu Rev Phytopathol 51: 245-266.

37. Tsuda K, Katagiri $F$ (2010) Comparing signaling mechanisms engaged in pattern-triggered and effector-triggered immunity. Curr Opin Plant Biol 13: 459465.

38. Pratelli R, Sutter JU, Blatt MR (2004) A new catch in the snare. Trends Plant Sci 9: 187-195.

39. Humphry M, Reinstädler A, Ivanov S, Bisseling T, Panstruga R (2011) Durable broad-spectrum powdery mildew resistance in pea er1 plants is conferred by natural loss-of-function mutations in PsMLO1. Mol Plant Pathol 12: 866-878.

40. Tsuda K, Sato M, Glazebrook J, Cohen JD, Katagiri F (2008) Interplay between MAMP-triggered and SA-mediated defense responses. Plant J 53: 763-775. 
41. Bari R, Jones JD (2009) Role of plant hormones in plant defence responses. Plant Mol Biol 69: 473-488.

42. Atkinson MM, Midland SL, Sims JJ, Keen NT (1996) Syringolide 1 triggers $\mathrm{Ca}^{2+}$ influx, $\mathrm{K}+$ efflux, and extracellular alkalization in soybean cells carrying the disease-resistance gene Rpg4. Plant Physiol 112: 297-302.

43. Hahlbrock K, Scheel D, Logemann E, Nürnberger T, Parniske M, et al. (1995) Oligopeptide elicitor-mediated defense gene activation in cultured parsley cells. Proc Natl Acad Sci USA 92: 4150-4157.

44. Neuhaus G, Neuhaus-Url G, Katagiri F, Seipel K, Chua NH (1994) TissueSpecific Expression of as-1 in Transgenic Tobacco. Plant Cell 6: 827-834.

45. Doke N, Miura Y, Sanchez LM, Park HJ, Toritake T, et al. (1996) The oxidative burst protects plants against pathogen attack: Mechanism and role as an emergency signal for plant bio-defense--a review. Gene 179: 45-51.

46. Baker CJ, Orlandi EW (1995) Active oxygen in plant pathogenesis. Annu Rev Phytopathol 33: 299-321.

47. Chandra S, Martin GB, Low PS (1996) The Pto kinase mediates a signaling pathway leading to the oxidative burst in tomato. Proc Natl Acad Sci USA 93: 13393-13397.

48. Wu G, Shortt BJ, Lawrence EB, Levine EB, Fitzsimmons KC, et al. (1995) Disease resistance conferred by expression of a gene encoding $\mathrm{H}_{2} \mathrm{O}_{2}$ generating glucose oxidase in transgenic potato plants. Plant Cell 7: 13571368 .

49. Broekaert WF, Delauré SL, De Bolle MF, Cammue BP (2006) The role of ethylene in host-pathogen interactions. Annu Rev Phytopathol 44: 393-416.
50. Glazebrook J (2005) Contrasting mechanisms of defense against biotrophic and necrotrophic pathogens. Annu Rev Phytopathol 43: 205-227.

51. Jabs T, Tschope M, Colling C, Hahlbrock K, Scheel D (1997) Elicitor-stimulated ion fluxes and $\mathrm{O}_{2}$ - from the oxidative burst are essential components in triggering defense gene activation and phytoalexin synthesis in parsley. Proc Natl Acad Sci USA 94: 4800-4805.

52. Park SW, Kaimoyo E, Kumar D, Mosher S, Klessig DF (2007) Methyl salicylate is a critical mobile signal for plant systemic acquired resistance. Science 318 113-116.

53. Balbi V, Devoto A (2008) Jasmonate signalling network in Arabidopsis thaliana: crucial regulatory nodes and new physiological scenarios. New Phytol 177: 301-318.

54. Grant M, Lamb C (2006) Systemic immunity. Curr Opin Plant Biol 9: 414-420.

55. Dempsey DA, Pathirana MS, Wobbe KK, Klessig DF (1997) Identification of an Arabidopsis locus required for resistance to turnip crinkle virus. Plant $\mathrm{J} 11$ : 301-311.

56. Summermatter K, Sticher L, Metraux JP (1995) Systemic Responses in Arabidopsis thaliana Infected and Challenged with Pseudomonas syringae pv syringae. Plant Physiol 108: 1379-1385.

57. Kloppholz S, Kuhn H, Requena N (2011) A secreted fungal effector of Glomus intraradices promotes symbiotic biotrophy. Curr Biol 21: 1204-1209.

58. Plett JM, Kemppainen M, Kale SD, Kohler A, Legué V, et al. (2011) A secreted effector protein of Laccaria bicolor is required for symbiosis development. Curr Biol 21: 1197-1203. 